RASĀYAN J. Chem.

Vol. 13 | No. 1 |593 - 600| January - March | 2020 ISSN: 0974-1496 | e-ISSN: 0976-0083 | CODEN: RJCABP

\title{
THE EXFOLIATION PROCESS OF SAWAHLUNTO COAL INTO GRAPHENE THROUGH THE MODIFIED HUMMER METHOD
}

\author{
V. Purwandari ${ }^{1}$, S. Gea ${ }^{2, *}$, B. Wirjosentono ${ }^{2}$, A. Haryono ${ }^{3}$, S. Rahayu ${ }^{2}$ \\ and Y. A. Hutapea ${ }^{2}$ \\ ${ }^{1}$ Postgraduate School, Department of Chemistry, Faculty of Mathematics and Natural Sciences, \\ Universitas Sumatera Utara, 20155, Indonesia \\ ${ }^{2}$ Department of Chemistry, Universitas Sumatera Utara, Jl. Bioteknologi No. 1 Medan 20155, \\ Indonesia \\ ${ }^{3}$ Research Center for Chemistry, Indonesian Institute of Sciences, Serpong, Indonesia \\ *E-mail: s.gea@usu.ac.id
}

\begin{abstract}
Sawahlunto is one of the coal-producing regions in Indonesia. Coal as an abundance of carbon content material is significantly drawing attention to be developed in certain material research. To begin, this research was aimed to exfoliate Graphene from Coal which was obtained from Sawahlunto, Indonesia by performing the modified hummer method. The Sawahlunto coal was treated and converted into graphite ( $\mathrm{g}$-Bb900) through the carbonization process at an optimum temperature of $900^{\circ} \mathrm{C}$. Then, the formation of graphene oxide $(\mathrm{GO}-\mathrm{Bb} 900)$ was performed using the modified hummer method and followed by the reduction process to finally result in the graphene $(\mathrm{G}-\mathrm{Bb} 900)$. Several characterizations have been performed to confirm the graphene produced. The results of XRD and FTIR analysis indicate a significant difference in chemical and structural changes between graphite, graphene oxide and graphene. Moreover, TEM analysis also displays a significant difference in morphology analysis result of graphite, graphene oxide, and graphene. To sum up, these results have been evaluated and analyzed to prove that the graphene was successfully obtained from Sawahlunto coal.
\end{abstract}

Keywords: Sawahlunto Coal, Exfoliation Process, Graphene, Modified Hummer Method

(C) RASĀYAN. All rights reserved

\section{INTRODUCTION}

Graphene is identified as a molecular sheet derived from graphite and possessing various beneficial applications, particularly for material sciences such as the development of nanocomposites, sensors, supercapacitors, hydrogen storage and optoelectronic devices. As a current two-dimensional material, graphene interests many researchers for its extraordinary chemical and physical properties. ${ }^{1-4}$ Graphene, which is a thin atomic sheet of carbon atoms with sp2 hybridization and tightly arranged in a framework like a two-dimensional (2D) honeycomb, can be fabricated through a chemical reduction process of graphene oxide, followed by sonication process. ${ }^{5,6}$ From graphite, the graphene layer is benefitted by its strong cohesive force, making it difficult to get the graphene exfoliation sheets. ${ }^{7,8}$ Therefore, it is crucial to perform graphene functionalization to reduce its cohesive force. ${ }^{9,10}$

The graphite oxide (GO) produced from the graphite oxidation process is having a hydrophilic functional group (-OH, epoxy, $-\mathrm{COOH})$ that encourages water pathway and graphene sheets to be easily separated through sonication process, which then results in a dispersed GO sheet in an aqueous medium. This GO exfoliation is commonly performed for various applications and/or with group functionality for particular applications. In terms of electrical conductivity, GO is an insulator. However, it will be a good conductor when it is reduced to be reduced graphene oxide ( $\mathrm{rGO}$ ) which commonly obtained by reduction process via Sodium Borohydride or hydrazine hydrate. ${ }^{11-14}$ Experimentally, GO can be manufactured through Rasayan J. Chem., 13(1), 593-600(2020)

http://dx.doi.org/10.31788/RJC.2020.1315473

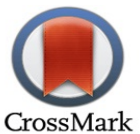


RASĀYAN J. Chem.

Vol. 13 | No. 1 |593 - 600| January - March | 2020

graphite oxidation with several methods developed by Brodie, Hummers, and Staudenmeier. Moreover, it still maintains a layered structure, but much lighter compared to graphite due to electronic conjugation loss from the oxidation process. ${ }^{7-15}$ Also, $(\mathrm{GO})$ is the most important precursor for producing graphene. ${ }^{16}$ To date, GO is generally synthesized by the graphite exfoliation method, which is Hummers modification method. ${ }^{16,17}$ Several carbon sources including hydrocarbons, graphite, natural biomaterials, and even plastic waste have been vastly utilized to produce graphene. ${ }^{18}$ However, the most abundant carbon source identified in the world has not been optimally used to manufacture graphene. It is coal, which has not been widely studied for making graphene recently. ${ }^{19,20}$

Coal has an abundant polyaromatic structure and is identified as similar to the $\mathrm{sp}^{2}$ bond of graphene. Therefore, coal can be potentially utilized as a starting material for fabricating graphene. ${ }^{21,22}$ Basically, coal is a molecular solid that has an imperfect structure while graphite has a solid lattice without weak bonds. It is known that chemical exfoliation is categorized as an effective method to produce huge amounts of graphene. ${ }^{23,24} \mathrm{Ye}$, et al., (2013) produced graphene using the sonication process of bituminous coal with sulphuric and nitric acid followed by the heating process at a temperature of $100-120^{\circ} \mathrm{C}$ for 24 hours. ${ }^{21}$ Furthermore, In Indonesia, an area called Sawahlunto is one of the coal-producing regions. Sawahlunto Coal with the classification of bituminous coal with a carbon content of $40-49 \%$ has a good potential to be a raw material for producing graphene. ${ }^{25}$

\section{EXPERIMENTAL}

\section{Materials}

Coal was obtained from Sawahlunto, West Sumatra, Indonesia. Sulphuric acid 98\%, potassium permanganate, sodium nitrate, hydrogen peroxide $30 \%$, hydrogen chloride $36 \%$, sodium hydroxide and sodium borohydride were originally purchased from Sigma Aldrich. Demineralized Water (DM) was separately purchased from Bratachem.

\section{Sawahlunto Coal Graphite Preparations}

Coal was ground into a powder with a Ballmill for 4 hours until fine coal powder was obtained. The size of the obtained coal powder was then uniformed using a 325 mesh sieve. Then, the coal powder was heated at a temperature of $125^{\circ} \mathrm{C}$ for 24 hours. Carbonization process of coal samples was conducted at temperatures of $400^{\circ} \mathrm{C}(\mathrm{Bb} 400), 600^{\circ} \mathrm{C}(\mathrm{Bb} 600), 900^{\circ} \mathrm{C}(\mathrm{Bb} 900)$ and $1200^{\circ} \mathrm{C}(\mathrm{Bb} 1200)$ respectively $[26,27]$. After the carbonization treatment, the coal samples were analyzed using the X-ray Diffraction analysis method (XRD). It was found that the optimum carbonization temperature was $900^{\circ} \mathrm{C}$ indicating the best crystallinity.

\section{Oxidation Process}

The exfoliation process was initiated with the oxidation process of Bb900 using the modified Hummers method. As many as 2 grams of $\mathrm{Bb} 900$ were inserted into a beaker glass which is placed inside an ice bath along with an addition of 4 grams of $\mathrm{NaNO}_{3}$ and $100 \mathrm{ml}$ of $\mathrm{KMnO}_{4}$. It was then stirred for 1 hour. The beaker was then removed from the ice bath and the temperature was maintained at less than $20^{\circ} \mathrm{C}$. After 24 hours of stirring process, the reaction mixture was added with $200 \mathrm{ml}$ of demineralized water. Then, the temperature was increased to $90-95^{\circ} \mathrm{C}$, and maintained from boiling for 2 hours. Then, an amount of $200 \mathrm{ml}$ of DM water was added and the stirring was carried on until the room temperature was reached. After that, $20 \mathrm{ml}$ of $30 \% \mathrm{H}_{2} \mathrm{O}_{2}$ was inserted to remove the remaining $\mathrm{KMnO}_{4}$. The reaction mixture was then washed with $\mathrm{HCl} 5 \%$ and $\mathrm{DM}$ water respectively until the neutral $\mathrm{pH}$ was obtained by the centrifugation process at $7200 \mathrm{rpm}$ for 15 minutes. ${ }^{4,11,20,28}$ The obtained deposits were collected and stirred with DM water then dialyzed for $7 \times 24$ hours to separate the graphite oxide suspension with unoxidized Bb900 graphite. Graphite oxide suspension was then dried at $100^{\circ} \mathrm{C}$ for 24 hours. Finally, graphite oxide powder (go-Bb900) was obtained.

\section{Exfoliation Process}

Graphene oxide was obtained through the exfoliation process. An amount of $5 \mathrm{mg}$ of go-Bb900 was taken and $50 \mathrm{~mL}$ of DM water was added then stirred for one hour. After that, the mixture was sonicated using 
RASĀYAN J. Chem.

Vol. 13 | No. 1 |593 - 600| January - March | 2020

the ultra-sonication process for one hour and the suspension of graphene oxide (GO-Bb900) was obtained..$^{10,15}$

\section{Reduction Process}

The reduction process of the exfoliation results (GO-Bb900) was carried out using the $1 \% \mathrm{NaBH}_{4}$ in $0.2 \%$ $\mathrm{NaOH}$. The mixture was stirred for 1 hour and $6 \mathrm{~N}$ of $\mathrm{HCl}$ was added dropwise until the air bubbles were disappeared. After that, the precipitate was formed and then washed with DM to reach neutral $\mathrm{pH}$. The precipitate was then dried at a temperature of $100^{\circ} \mathrm{C}$ for 12 hours. Finally, the graphene powder was successfully manufactured from Sawahlunto coal (G-Bb900). ${ }^{11}$

\section{Sawahlunto Coal Carbonization}

\section{RESULTS AND DISCUSSION}

This research produces several findings and results that will lead to a conclusion that will be made. Based on Figure 1, it is seen that the 29 peak of identified from the five samples $(\mathrm{Bb}),(\mathrm{Bb} 400),(\mathrm{Bb} 600)$, $(\mathrm{Bb} 900)$ and $(\mathrm{Bb} 1200)$ were recorded at almost the same angle, around $24^{\circ}$. The $\mathrm{Bb} 900$ has an intensity of 399 , and it appears that a new 29 angle is at $43.8^{\circ}$ with an intensity of 128 . Bb1200 also has a peak of 29 which is similar to $\mathrm{Bb} 900$ following a new peak that appears at an angle of $43.7^{\circ}$ with an intensity of 15 . However, Bb1200 does not have FWHM (peak at half the maximum sample), while Bb900 at peak $24^{\circ}$ with FWHM equal to 5.48 .

Moreover, in Fig.-1, it can be seen that coal which had been treated through a carbonization process at $900^{\circ} \mathrm{C}$ showed a higher crystallinity than the others. Also, the wider the peak of the XRD spectrum, the smaller the crystallinity of graphite recorded.

During the carbonization treatment, the volatile components and the other components including hydrogen, oxygen and unorganized hydrocarbons will evaporate due to the pyrolysis of coal. The accumulation of carbon formed a bonding between each other to form crystals that consisted of graphite crystal structures. ${ }^{29}$ When carbonization treatment was conducted, the removal of water and decomposition of coal occurred and resulting tar, methanol, phenol, and others. It leaves the carbon content with about $80 \%$. The carbon element itself was obtained at a temperature of $400-600{ }^{\circ} \mathrm{C} .{ }^{30}$ Based on the XRD spectra, it was found that the Sawahlunto coal that processed with the carbonization treatment at $900^{\circ} \mathrm{C}$ has the best crystallinity. This coal showed a peak at $24.3^{\circ}$ and a new peak (peak shoulder) at $43^{\circ}$. Both of these peaks are typical peaks of graphite. ${ }^{20}$

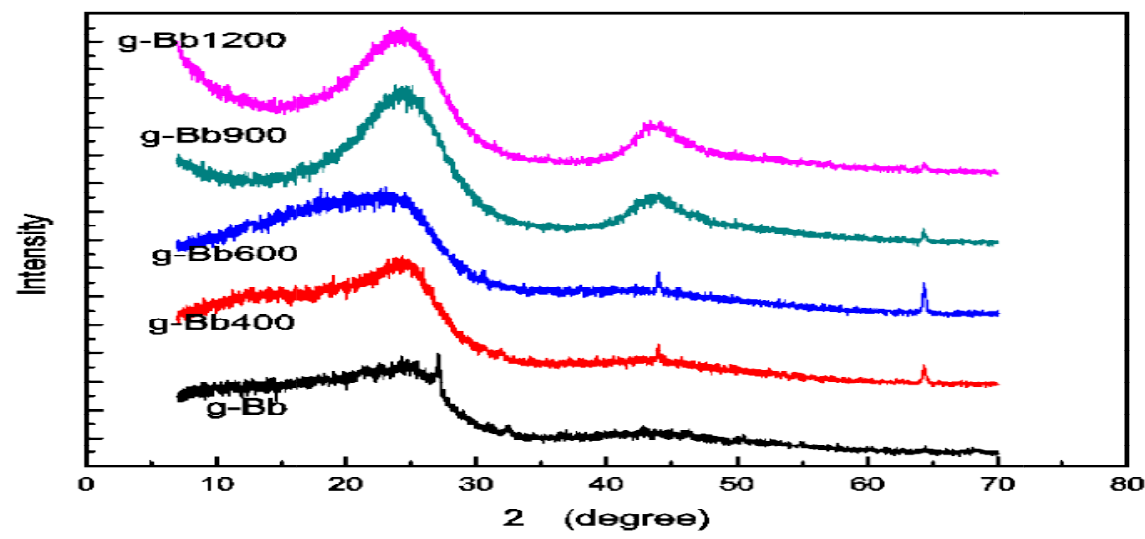

\section{Proximate Test on Bb900}

Fig.-1: Crystallographic of g-Bb, g-Bb400, g-Bb600, g-Bb900, g-Bb1200

After the optimum Sawahlunto coal was obtained $(\mathrm{Bb} 900)$, a proximate test was conducted to determine the fix carbon content in Bb900. Before carbonization was carried out, the carbon content of the Sawahlunto coal was in the range of $40.79-49.67 \%$. But after the carbonization treatment, the carbon content in $\mathrm{Bb} 900$ was discovered to be increased up to $73.79 \%$. This is due to the occurrence of the 
RASĀYAN J. Chem.

Vol. 13 | No. 1 |593 - 600| January - March | 2020

dehydrogenation process, and as the impact, the bonds between the carbon forming crystals and the decomposition occurred.$^{30}$

\section{Graphite Exfoliation Process (g-Bb900) to Graphene (G-Bb900)}

The exfoliation process was begun with the oxidation process of $\mathrm{g}$-Bb900 through the modified Hummers method and graphite oxide (go-Bb900) was fabricated. The change in the surface morphology of g-Bb900 along with GO-Bb900 was observed using Scanning Electron Microscopy as displayed in Fig.-2, and followed by contexture analysis using Energy Dispersive Spectroscopy, shown in Fig.-3.

\section{SEM EDX Analysis}

Figure-2 shows that g-Bb900 has a larger and irregular size of particles while GO-Bb900 has a finer and wrinkle particle size. Moreover, the G-Bb900 was indicated to have a smooth and regular morphology.

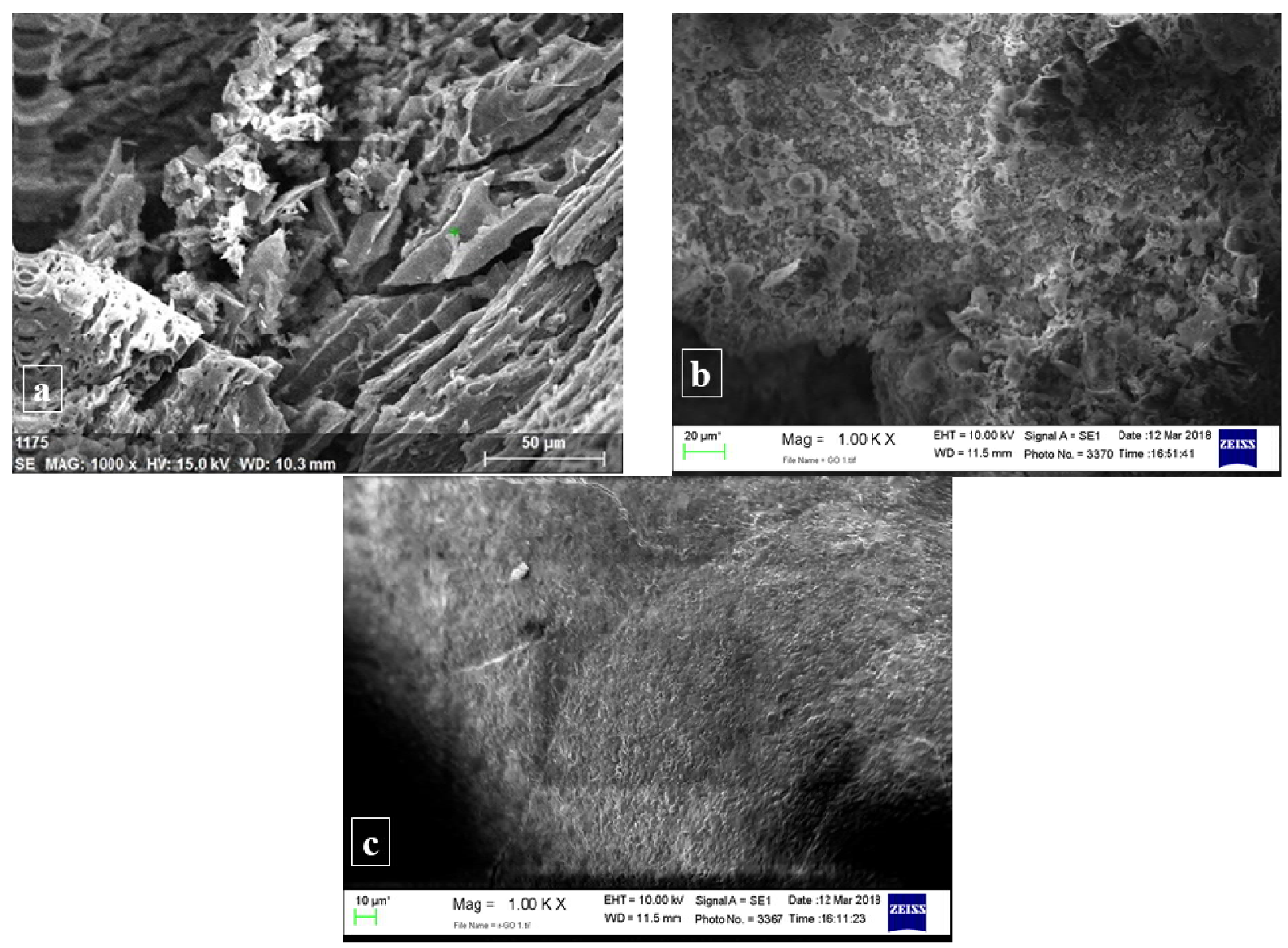

Fig.-2: The Surface Structure of Coal Graphite (g-Bb900) with 1000x agnification

Figure-2 shows that the surface structure of coal graphite (g-Bb900) with $1000 \mathrm{x}$ magnification has a particle diameter of about $19.25 \mu \mathrm{m}$. Graphene oxide (GO-Bb900) with the same magnification of 1000x shows two smaller particle diameter $( \pm 2.0 \mu \mathrm{m})$ and visible surface shrinking. Graphene (G-Bb900) with a magnification of 1000x also shows a finer particle diameter size $( \pm 20 \mathrm{~nm})$ with a smooth surface neatly arranged. Figure- 3 is the identification of the main carbon elements comprising coal graphite material (g$\mathrm{Bb} 900$ ), graphene oxide (GO-Bb900), and graphene (G-Bb900) using EDX SEM. The results are in the Table-1.

The oxidation process of g-Bb900 becoming GO-Bb900 was proven through the element composition analysis using the EDX analysis as displayed by figure 3 . Moreover, table 1 clearly describes the content 
RASĀYAN J. Chem.

Vol. 13 | No. 1 |593 - 600| January - March | 2020

of carbon and oxygen possessed during the exfoliation process. The results indicate that the carbon composition decreases by $35 \%$ and an increase in the composition of the $19 \%$ oxygen atom are recorded. Furthermore, the reduction (b)GO-Bb900 - (c)G- Bb900 was proven by the decrease of oxygen and the increase in carbon content. ${ }^{15}$
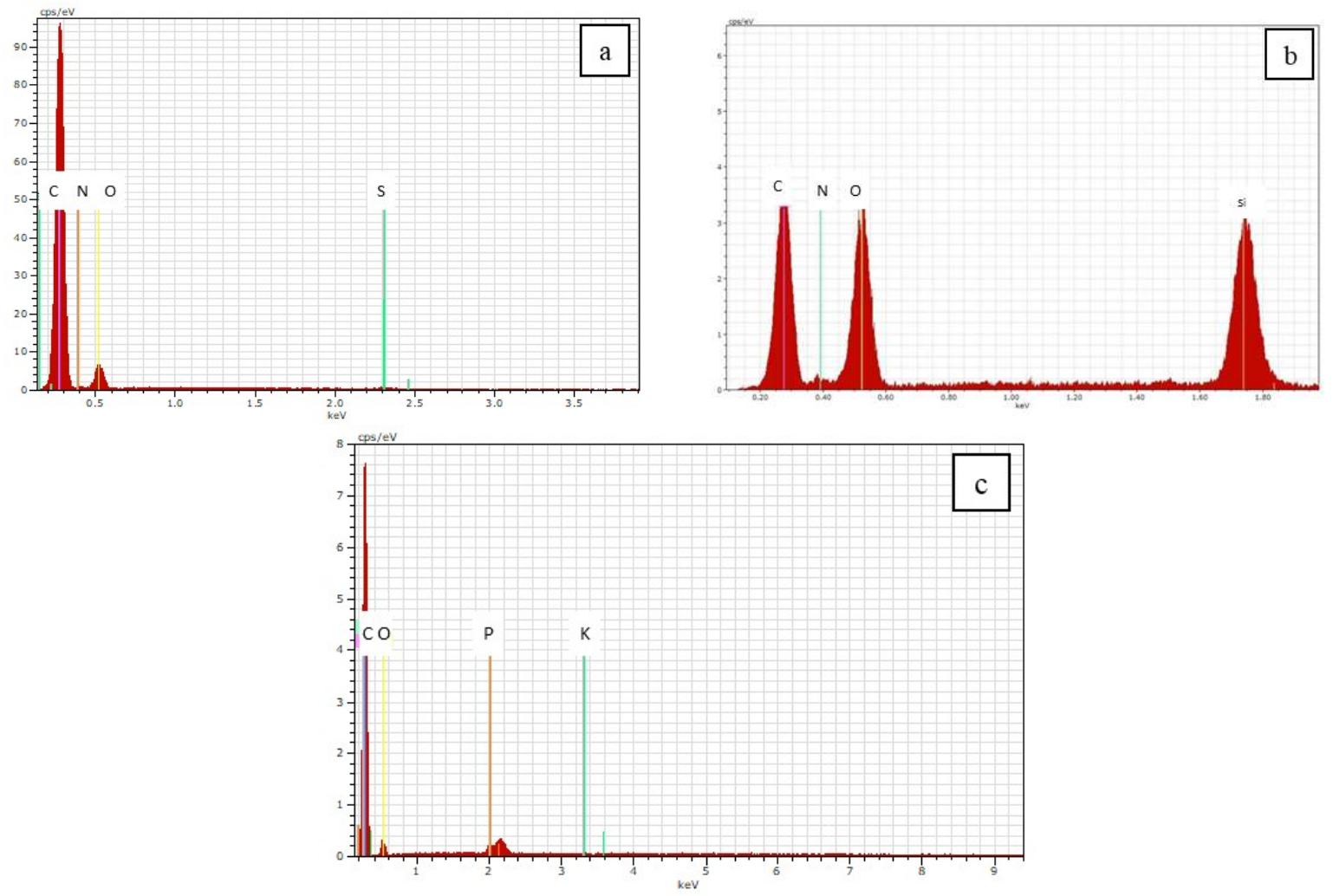

Fig.-3: Identification of the Main Carbon Elements Comprising Coal Graphite Material (g-Bb900), Graphene Oxide (GO-Bb900), and Graphene (G-Bb900) using EDX SEM

Tabel-1: Carbon and Oxygen Elements g-Bb900, GO-Bb900, and G-Bb900

\begin{tabular}{c|c|c|c|c}
\hline \multirow{2}{*}{ Sample } & \multicolumn{3}{c}{ Elements } \\
\cline { 2 - 5 } & \multicolumn{2}{|c|}{ Carbon } & \multicolumn{2}{c}{ Oxygen } \\
\cline { 2 - 5 } & Weight (\%) & & 16.49 & \\
\hline Sawahlunto Coal (g-Bb900) & 77.46 & & 34.64 & \\
\hline Graphene Oxide (GO-Bb900) & 42.01 & & 11.62 & \\
\hline Graphene (G-Bb900) & 87.47 & & & \\
\hline
\end{tabular}

\section{XRD Analysis}

Figure-4 shows that coal graphite (g-Bb900) with a peak of 2 thetas at $24^{\circ}$ shifts left to graphene oxide (GO-Bb900) with a diffraction peak of $11^{\circ}$ after the oxidation process. The diffraction peak shifts to the right $\left(23.8^{\circ}\right)$ after going through the reduction process $(\mathrm{G}-\mathrm{Bb} 900)$.

Furthermore, the XRD spectra in Fig.-4 showed the different distinctive peak among graphite, graphite oxide and graphene from the Sawahlunto coal. g-Bb900 is amorphous graphite with a peak at $24.3^{\circ}$ with the inter-particle distance of $3.61 \mathrm{~A}$. The peak shifting occurred after the oxidation process that showed by the GO-Bb900 spectrum with a peak at $11^{\circ}$ and the inter-particle distance of $7.97 \mathrm{~A}$. This is a typical peak of graphene oxide and the increase in the distance between particles is caused by the oxygen functional groups and hydrogen bonds with water that formed between the layers of graphite structure. The reduction process on GO-Bb900 changed the peak to be $23.8^{\circ}$ and the distance between particles became $3.73 \mathrm{~A}$, the reduction process occurred along with the loss of oxygen functional groups and 
RASĀYAN J. Chem.

Vol. 13 | No. 1 |593 - 600| January - March | 2020

hydrogen bonds between the carbon layers. This was confirmed by the insoluble of G-Bb900 in water. In the end, the peak produced by the G-Bb900 was no longer as sharp as the g-Bb900.

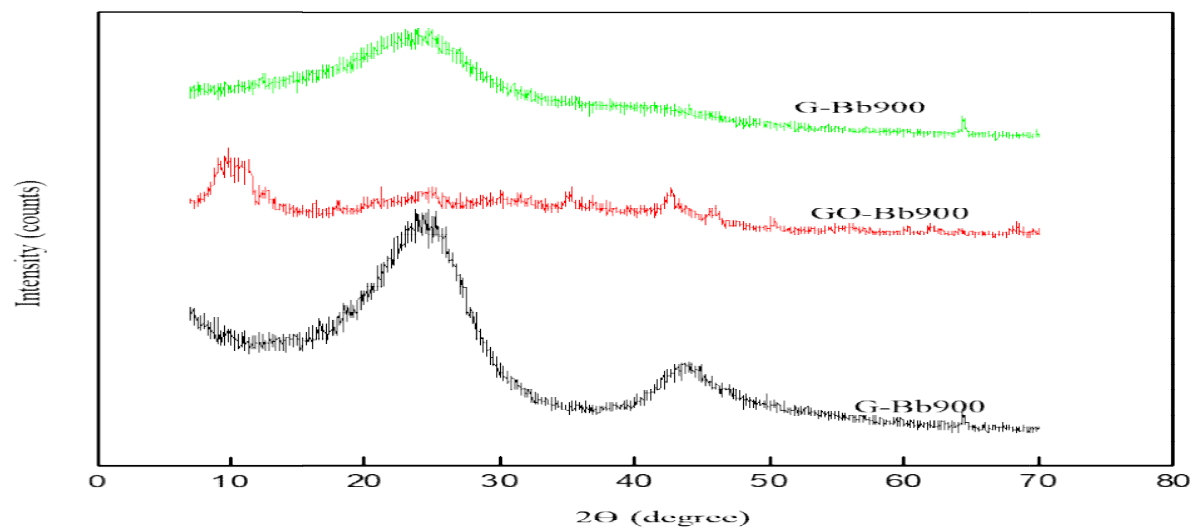

Fig.-4: Crystallographic of g-Bb900, GO-Bb900, G-Bb900

\section{FTIR Analysis}

The FTIR spectra in Fig.-5 (GO-Bb900) show a peak of $3354 \mathrm{~cm}^{-1}$ which confirms the presence of $-\mathrm{OH}$ group, the peak of $2086 \mathrm{~cm}^{-1}$ confirms the presence of carboxylic acid group $(\mathrm{COOH})$, furthermore, a peak at $1621 \mathrm{~cm}^{-1}$ indicates vibration $\mathrm{C}=\mathrm{C}$ of the aromatic ring, $1136 \mathrm{~cm}^{-1}$ is a vibration of $\mathrm{C}=\mathrm{O}$ derived from carboxylic acid groups, aldehydes and ketones, $1040 \mathrm{~cm}^{-1}$ indicates the presence of $\mathrm{C}-\mathrm{OH}$. The weak peak of $3313 \mathrm{~cm}^{-1}$ in the spectra (G-Bb900) indicates the $-\mathrm{OH}$ group, measuring $1036 \mathrm{~cm}^{-1}$ is a bond of $\mathrm{C}=\mathrm{CH}$ or $\mathrm{Ar}-\mathrm{H}$.

The formation of graphene oxide (GO-Bb900) was also confirmed from the FTIR spectra as shown in Fig.-5. GO-Bb900 Spectra resulted in a peak at $3354 \mathrm{~cm}^{-1}$ indicated the $-\mathrm{OH}$ vibration that assumed as confirmation of oxygen atoms from the functional groups of GO. The peak at $2086 \mathrm{~cm}^{-1}$ confirms the hydrogen bonds that occur from the carboxylic acid groups derived from $\mathrm{GO}$. The $\mathrm{C}=\mathrm{C}$ vibration that derived from an aromatic ring was recorded at a wavelength of $1621 \mathrm{~cm}^{-1}$. The peak of sharp absorption at $1163 \mathrm{~cm}^{-1}$ represents the $\mathrm{C}=\mathrm{O}$ bond vibration from the functional group of carboxylic acids, aldehydes, and ketones. Finally, the vibration of C-OH was recorded at a wavelength of $1040 \mathrm{~cm}^{-1} .{ }^{16}$

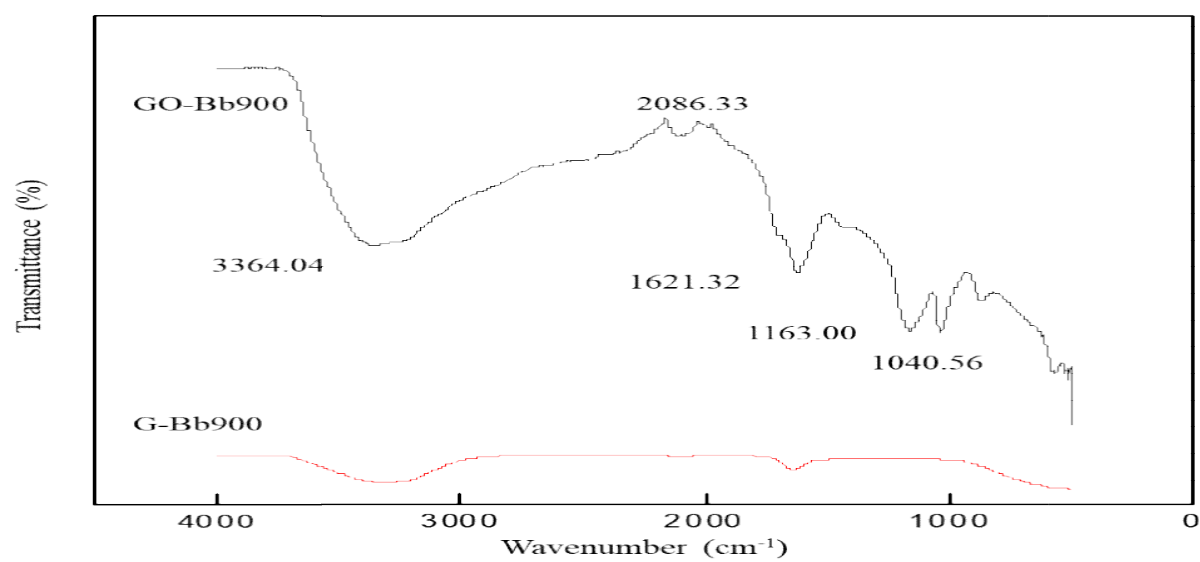

Fig.-5: FTIR Analysis Spectra of GO-Bb900 and G-Bb900

There were also several spectra recorded for G-Bb900. The peak of $3319 \mathrm{~cm}^{-1}$ indicated that the $-\mathrm{OH}$ group can still be found in this material which may be due to hydrogen bonding from the remaining water molecules in graphene (G-Bb900). Another peak recorded is at a wavelength of $1036 \mathrm{~cm}^{-1}$ which corresponds to a $\mathrm{C}=\mathrm{CH}$ bond or $\mathrm{Ar}-\mathrm{H}$ of graphene.

To sum up, the FTIR test results prove that graphite coal ( $\mathrm{g}$-Bb900) has been successfully oxidized into graphene oxide (GO-Bb900) and graphene oxide (GO-Bb900) has been completely reduced to form graphene (G-Bb900). 
RASĀYAN J. Chem.

Vol. 13 | No. 1 |593 - 600| January - March | 2020

\section{TEM Analysis}

Figure-6(a) shows that coal graphite consists of many layers (overlapping), which indicates that graphite has a layered structure. Also, in Fig.-6(b), it can be seen that the structure of graphene oxide is still stacked and not separated to form a single layer. This is mainly caused by the oxygen functional groups attached to the plane of the graphene oxide layer. On the other hand, figure 6(c) reveals that graphene oxide has been reduced and these transparent layers are still existed as a bundle of layers and can be categorized as multilayer graphene. ${ }^{17}$ Transmission electron microscopy (TEM) analysis confirmed the graphene and graphene oxide thickness. The stable and transparent appearance of graphene sheets observed from TEM analysis is confirming the formation of single-layer graphene. ${ }^{8}$ To conclude, Fig.- 6 indicates that graphene obtained from Sawahlunto coal was a multilayer graphene. ${ }^{7}$

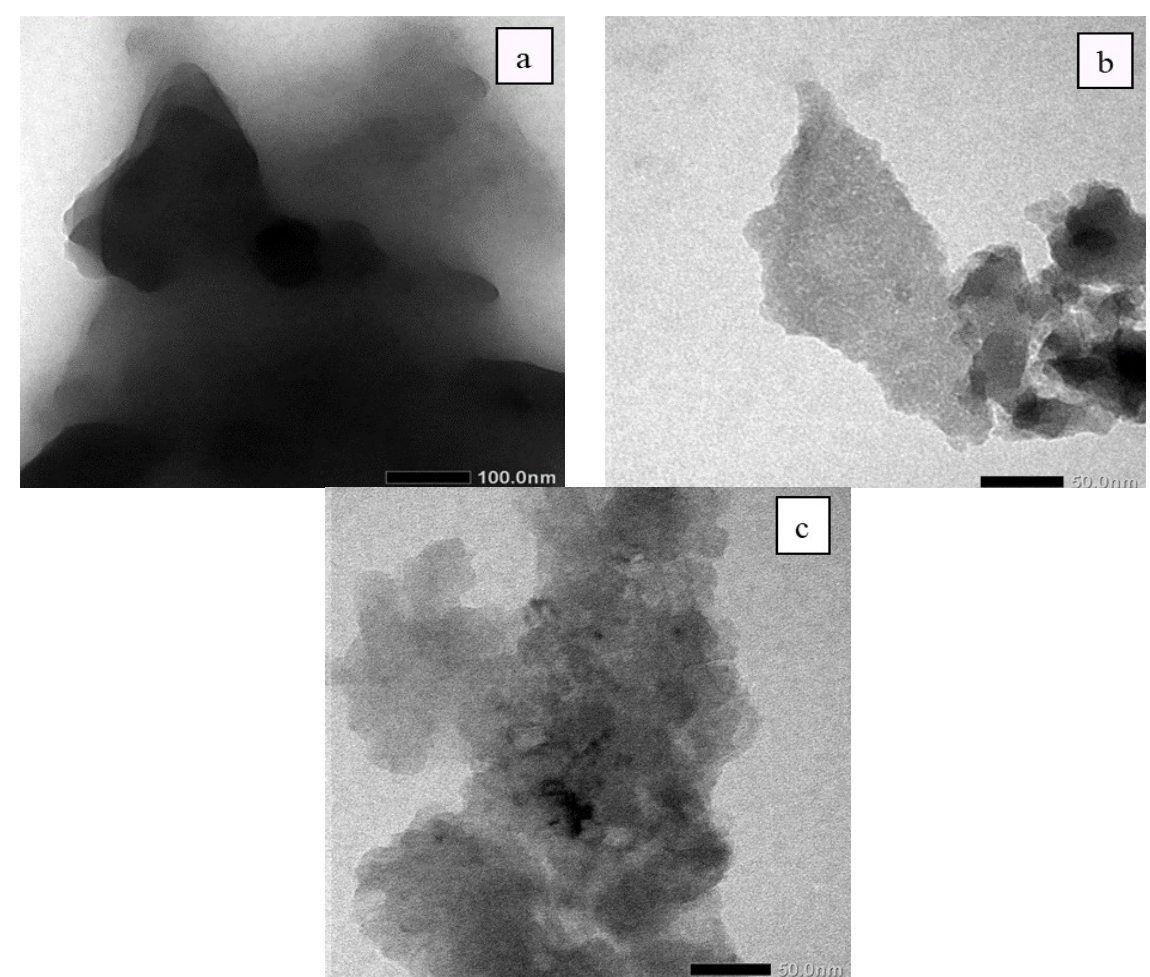

Fig.-6: The TEM Image of (a) g-Bb900, (b) GO-Bb900, (c) G-Bb900

\section{CONCLUSION}

Graphene was successfully fabricated from Sawahlunto coal using the modified Hummers method. The graphene formed was confirmed chemically and structurally via XRD and FTIR analysis method. Moreover, the resulting graphene morphology changes were revealed by SEM and TEM analysis. XRD analysis showed a shift of $2 \theta$ diffraction peaks and changes in inter-particle distance after the oxidation and reduction processes. FTIR analysis result also proves that the reduction process has occurred, respected to the loss of oxygen functional groups on the graphene spectrum. Morphology analysis of SEM and TEM showed that graphite exfoliation was completely performed to produce graphene.

\section{ACKNOWLEDGMENT}

The author would like to thank the Ministry of Research and Technology of the Directorate of Higher Education of Indonesia who has provided research funding via "Doctoral Dissertation Research 2018" scheme with contract number of 0045/E3/LL/2018.

\section{REFERENCES}

1. Q. Zhou, Z. Zhao, Y. Zhang, B. Meng, A. Zhou and J. Qiu, Energy \& Fuels, 26, 5186(2012), DOI:10.1021/ef300919d

2. K.S. Novoselov, V.I. Fal'ko, L. Colombo, P.R. Gellert, M.G. Schwab and K.A. Kim, Nature, 490, 
RASĀYAN J. Chem.

Vol. 13 | No. 1 |593 - 600| January - March | 2020

192(2012), DOI:10.1038/nature11458

3. A. Krueger, Beilstein Journal of Organic Chemistry, 10, 1785(2014), DOI:10.3762/bjoc.10.186

4. Y. Zhu, S. Murali, W. Cai, X. Li, J.W. Suk, J.R. Potts and R.S. Ruoff, Advanced Material, 22, 3906(2010), DOI:10.1002/adma.201001068

5. Y. Zhan, J. Wu, H. Xia, N. Yan, G. Fei and G. Yuan, Macromolecular Materials and Engineering, 296, 590 (2011), DOI:10.1002/mame.201000358

6. T.N. Zhou, X.D. Qi and Q. Fu, Express Polymer Letters, 7(9), 733(2013), DOI:10.3144/expresspolymlett.2013.72

7. S. Stankovich, D.A. Dikin, R.D. Piner, K.A. Kohlhaas, A. Kleinhammes, Y. Jia, Y. Wu, S.T. Nguyen and R.S. Ruoff, Carbon, 45,1558(2007), DOI:10.1016/J.CARBON.2007.02.034

8. D.D.L. Chung, Journal of Material Science, 51, 554(2016), DOI:10.1007/s10853-015-9284-6

9. Y. Hernandez, V. Nicolosi, M. Lotya, F.M. Blighe, Z. Sun, S. De, et al., Nature Nanotechnology, 3, 563 (2008), DOI:10.1038/nnano.2008.215

10. M. Cai, D. Thorpe, D.H. Adamson and H.C. Schniepp, Journal of Material Chemistry, 22, 24992 (2012), DOI: $10.1039 / \mathrm{c} 2 \mathrm{jm} 34517 \mathrm{j}$

11. H. Shin, K.K. Kim, A. Benayad, S. Yoon, H.K. Park, I. Jung, et al., Advanced Functional Materials, 19, 1987(2009), DOI:10.1002/adfm.200900167

12. R.K. Layek and A.K. Nandi, Polymer, 54, 5087(2013), DOI:10.1016/J.POLYMER.2013.06.027

13. J. Shen, Y. Hu, C. Qin and M. Ye, Small, 5, 82 (2009), DOI:10.1002/smll.200800988

14. S. Araby, Q. Meng, L. Zhang, H. Kang, P. Majewski, Y. Tang, et al., Polymer, 55, 201(2014), DOI:10.1016/J.POLYMER.2013.11.032.

15. D.C. Marcano, D.V. Kosynkin, J.M. Berlin, A. Sinitskii, Z. Sun, A. Slesarev A, L.B. Alemany, W. Lu and J.M. Tour, ACS Nano, 4, 4806(2010), DOI:10.1021/nn1006368

16. N. Syakir, R. Nurlina, S. Anam, A. Aprilia and S. Hidayat, Jurnal Fisika Indonesia, XIX, 26 (2015)

17. M.F.R. Hanifah, J. Jaafar, M. Aziz, A.F. Ismail, M.A. Rahman and M.H.D. Othman, Jurnal Teknologi, 74, 35(2015), DOI:10.11113/jt.v74.3555

18. J. Phiri, P. Gane and T.C. Maloney, Material Science and Engineering B, 215, 9(2017), DOI:10.1016/J.MSEB.2016.10.004

19. C.A. Strydom, J.R. Bunt, H.H. Schobert and M. Raghoo, Fuel Processing Technology, 92, 764 (2011), DOI: 10.1016/J.FUPROC.2010.09.008

20. Y. Wu, Y. Ma, Y. Wang, L. Huang, N. Li, T. Zhang, et al., Journal of Nanoscience and Nanotechnology, 13, 929 (2013), DOI:10.1166/jnn.2013.6001

21. R. Ye, C. Xiang, J. Lin, Z. Peng, K. Huang, Z. Yan, et al., Nature Communication, 4(2943), 1(2013), DOI: $10.1038 /$ ncomms3943

22. Y. Zhang, K. Zhang, K. Jia, G. Liu, S. Ren, K. Li, X. Long, M. Li and J. Qiu, Fuel, 241, 646(2019), DOI:10.1016/J.FUEL.2018.12.030

23. S. E. Kumar, V. Sivasankar, R. Sureshbabu, S. Raghu and A.R. Kalaivani, Advanced Material Letter, 8, 239 (2017), DOI:10.5185/amlett.2017.7048

24. T. Kuila, S. Bose, A.K. Mishra, P. Khanra, N.H. Kim and J.H. Lee, Progress in Material Science, 57, 1061(2012), DOI:10.1016/J.PMATSCI.2012.03.002

25. V. Purwandari, S. Gea, B. Wirjosentono and A. Haryono, AIP Conference Proceeding, 2049, 020065(2018), DOI:10.1063/1.5082470

26. S. Darmawan, N.J. Syafii, A. Wistara and G. Pari, Jurnal Penelitian Hasil Hutan, 33, 81(2015)

27. M.J. Rampe, B. Setiaji and W. Trisunaryanti, Chemistry Progress, 7(2), 74(2014), DOI: 10.35799/cp.7.2.2014.7470

28. W. Gao, Graphene oxide, Springer International Publishing, Cambridge, p.61-95(2015), DOI:10.1007/978-3-319-15500-5_3

29. X. Chai, H. He, H. Fan, X. Kang, X and Song, Bioresource Technology, 282, 142(2019), DOI:10.1016/J.BIORTECH.2019.02.126

30. C.J. Donahue and E.A. Rais, Journal of Chemical Education, 86(2) 222(2009), DOI:10.1021/ed086p222

[RJC-5473/2019] 